\title{
MATHIAS JOSÉ VELHO E SEUS ESCRAVOS: O INVENTÁRIO COMO FONTE DE PESQUISA
}

\author{
Emanuele Haag ${ }^{1}$ \\ Olgário Paulo Vogt $t^{2}$ \\ Roberto Radünz ${ }^{3}$
}

\begin{abstract}
RESUMO
O inventário, produzido primeiramente como um documento de caráter jurídico-civil, quando bem analisado, pode servir para diferentes pesquisas de caráter histórico. O presente artigo tem como base empírica o inventário post-mortem do estancieiro Mathias José Velho, realizado entre os anos de 1876 a 1879. Destaca-se na relação de bens do inventariado os escravos e os ingênuos. Esse fato é considerável haja vista que a Lei Rio Branco foi promulgada no ano de 1871, o que deixa em questão o futuro dessas crianças. Esses elementos são problematizados no presente artigo no contexto da escravidão no sul do Brasil.
\end{abstract}

Palavras-chave: Inventário. Escravidão. Mathias José Velho.

\begin{abstract}
The inventory, first produced as a document of legal, civil, when properly analyzed, can serve different research historical character. This article is based on empirical inventory postmortem rancher Mathias José Velho, performed between the years 1876 to 1879 stands out in relation to the goods inventoried slaves and naive. This fact is significant considering that the Rio Branco Law was enacted in 1871, leaving in question the future of these children. These elements are problematized in this article in the context of slavery in southern Brazil.
\end{abstract}

Keywords: Inventory. Slavery. Mathias José Velho.

\section{A IMPORTÂNCIA DE TRABALHAR COM INVENTÁRIOS}

O inventário é um documento exigido pelo Estado através do Poder Judiciário, no qual se relacionam todos os bens deixados por um indivíduo por ocasião de seu falecimento para tornar oficial a partilha dos bens entre os herdeiros (TEIXEIRA, 2012, p. 64). Instrumentos de caráter material, conforme Daumard (1984, p. 113), os inventários, além do nome do inventariante, indicam o nome do inventariado, descrevem os bens, a data do óbito, o local e a causa-mortis. Também constam informações como o estado civil do falecido, o nome do cônjuge, a afiliação, a existência de herdeiros, o seu número (se diretos ou colaterais), seus

\footnotetext{
1 Acadêmica do curso de História da Universidade de Santa Cruz do Sul - UNISC. <emanuele.haag@hotmail.com>

${ }^{2}$ Professor do Programa Pós-Graduação em Desenvolvimento Regional e pesquisador da Universidade de Santa Cruz do Sul - UNISC. <olgario@unisc.br>

${ }^{3}$ Professor e pesquisador da Universidade de Santa Cruz do Sul - UNISC e da Universidade de Caxias do Sul UCS. <radunz@unisc.br>
} 
nomes, o sexo, o estado civil, a idade, o grau de parentesco, legitimidade e uma relação de dívidas. Antigamente, o momento de se proceder ao pedido de um inventário era de incerteza para a família, já que o falecimento de um dos cônjuges trazia a consequente diminuição do conjunto dos bens.

O tempo da duração do inventário variava conforme a situação, pois tanto herdeiros menores quanto conflitos familiares podiam prolongá-lo em tempo e volume. Executado pelos tabeliões do judiciário, compunha-se da abertura, da avaliação dos bens (móveis, moventes e semoventes), documentos comprobatórios com avaliação das dívidas e partilha dos bens.

Segundo Magalhães (1989), o inventário é uma fonte diversificada, que permite o estudo de várias parcelas da população. "É como se tivéssemos em mãos uma câmera indiscreta vasculhando os meandros da casa, o vestuário, o mobiliário, o vasilhame, a despensa, o quintal, o sítio, as datas de minerar e, sobretudo, a mão-de-obra" (MAGALHÃES, 1989, p. 31-32). Enquanto fonte, os inventários post mortem não permitem apenas análises de caráter econômico, embora seja essa uma tendência muito forte. A partir deles é possível decifrar características sociais, culturais, religiosas e familiares de determinados grupos sociais, sendo um traço muito marcante a análise da escravidão em seus mais variados aspectos, como as condições de vida às quais eram submetidos os escravos e seus descendentes.

A base empírica principal utilizada neste artigo é constituída do inventário de Mathias José Velho, abastado e importante estancieiro estabelecido no município de Rio Pardo. Procura-se, nesse artigo, abordar especificamente a questão dos escravos ingênuos arrolados no inventário, isto é, os filhos de escravas nascidos após a promulgação da Lei do Rio Branco, mais conhecida como Ventre Livre. Além disso, objetiva-se discutir a situação dos ingênuos contabilizados no inventário com valores determinados.

\section{MATHIAS JOSÉ VELHO, O PERSONAGEM}

Mathias José Velho foi um estancieiro nascido em Mostardas, Província de São Pedro do Rio Grande do Sul, em 1792. Filho de Mathias Velho e Rita Maria Ferreira Durante, teve seis irmãs e um irmão. Foi agraciado com o título honorífico de major, mas supõe-se que tenha sido apenas para homenageá-lo, pois não teve grande representatividade política na região e não foi atuante na Guarda Nacional. 
Casou-se no ano de 1827 com Luciana Francisca da Terra (1806-1888), em Rio Pardo, tendo com ela 11 filhos. Faleceu no dia 25 de março de 1875 na Estância Nossa Senhora da Vitória às 6 horas da tarde, com 73 anos de idade. A causa mortis foi uma pneumonia dupla, de acordo com o que consta no livro de registro de sepultamento existente no Arquivo Histórico Municipal de Rio Pardo. Foi encomendado e sepultado às dez horas da manhã no Cemitério Público de Rio Pardo no jazigo número 829, com atestado do Doutor Antonio Ferreira de Andrade Neves. Segundo o registro assinado pelo vigário João Baptista da Motta Velloso, "o falecido não teria recebido o sacramento da extrema unção por não ter pedido".

Em vida, o Major acumulou muitos bens que estão descritos no seu inventário. Sua riqueza ficou demonstrada também nas tintas de dois quadros que estão guardados no Museu Barão do Santo Ângelo, na cidade de Rio Pardo. Essas pinturas, feitas pelo italiano Frederico Trebbi, retratam Mathias José Velho e sua esposa. As telas mostram a opulência da família do estancieiro, nas quais Dona Luciana é retratada com uma roupa muito elegante, destacando-se as joias, os brincos e o broche preso ao vestido, provavelmente objetos de ouro. Observa-se, ainda, no quadro de Mathias, uma corrente na frente do paletó, muito provavelmente um relógio de bolso.

\section{Fotografia 1- Mathias José Velho e Luciana Francisca da Terra Velho}

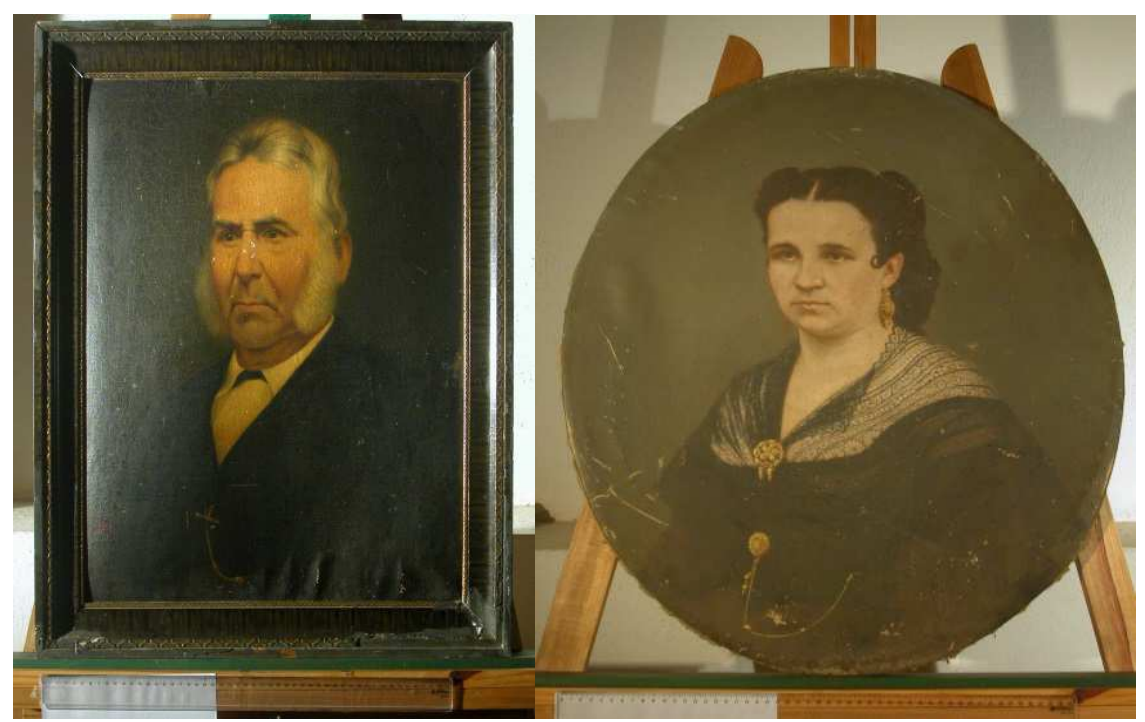

Fonte: Museu Barão do Santo Ângelo, 2013.

Foto: José Martinho Rodrigues Remedi

Nos anos de 1800, apenas pessoas muito abastadas possuíam dinheiro suficiente para posar para um pintor e, conforme Bohns (2005, p. 58), Trebbi foi autor de inúmeros retratos 
da burguesia ascendente após se radicar no interior da província, incluindo novos barões e viscondes que lutavam para manter a tradição imperial.

Esse tipo de documento iconográfico permite ver detalhes sociais da elite da época. Slenes (1985, p. 174-175), discutindo a fotografia como carte de visite no final do período escravista, mostra a importância das representações que estão por trás do registro iconográfico, salientando os detalhes e os acessórios decorativos que por vezes passam despercebidos ao observador comum.

\section{O INVENTÁRIO}

O inventário iniciou-se em 08 de março de 1876, sendo concluído apenas em 1879 , devido ao fato do inventariado possuir herdeiros menores de idade. Destaca-se que a demora ocorreu em razão de um dos filhos do estancieiro, Mathias José Velho Neto, já ser falecido e possuir filhos menores, transcorrendo o inventário na vara de Órfãos de Rio Pardo, na Província de São Pedro do Rio Grande do Sul.

O inventário de Mathias Velho é bastante volumoso, vista a quantidade de bens. Neste artigo utilizam-se apenas os dados que focam os bens da Estância Nossa Senhora da Vitória.

Antes de pertencer a Mathias José Velho, a Nossa Senhora da Vitória pertenceu a Pedro Rodrigues Chaves, o Barão de Quaraí, que a vendeu em 29 de dezembro de 1857 (SPENNER, 2013, p. 81-82). Este empreendimento possuía oito léguas de campo, equivalentes a 35.216 hectares de terra. Constituía-se um grande patrimônio, ao qual se somavam as demais benfeitorias, os animais, a casa-sede e os muitos utensílios e móveis ali existentes (SPENNER, p. 84). A relação dos bens do Major revela uma quantidade imensa de móveis, apetrechos de cozinha, prataria e material de lida na estância. Os materiais das mobílias (jacarandá, mogno, mármore, cedro) indicam a fortuna do proprietário.

Diante da análise da Tabela 1 é possível constatar que, embora Mathias Velho fosse um dos maiores criadores de gado da região, chegando a um rebanho de mais de 15 mil animais, seu bem mais precioso era a terra.

Tabela 1 - Descrição dos bens da Fazenda Nossa Senhora da Vitória

\begin{tabular}{cc}
\hline Bens & Valor em Mil Reis \\
\hline Escravos & $41: 025 \$ 000$ \\
Animais & $150: 986 \$ 000$
\end{tabular}


Móveis e equipamentos

Terras

Total
$4: 399 \$ 095$

320:000\$000

$516: 410 \$ 095$

Fonte: elaborado a partir dos dados do inventário $\mathrm{n}^{\circ} 803,1876$.

Segundo Christillino (2010) e Zetter (2011), Mathias José Velho é citado em publicações como um dos maiores criadores de gado da província no século XIX, sendo que seu rebanho contava com mais de 15 mil cabeças entre cavalos, reses, novilhas e burros. Para um rebanho desse porte era necessário uma grande extenção de terra e trabalhadores para as lidas diárias no campo, sendo que os escravos supriam em parte essa necessidade, de forma que contava com 53 cativos, entre homens, mulheres e crianças.

Durante o período colonial e imperial do Brasil o escravo era considerado uma mercadoria. Pelo direito de propriedade que existia, os senhores donos de escravos podiam “alugá-los, emprestá-los, vendê-los, dá-los, aliená-los, legá-los, constituí-los em penhor ou hipoteca, dispor dos seus serviços, desmembrar da sua propriedade ou usufruto, exercer enfim todos os direitos legítimos de verdadeiro dono ou proprietário" (MALHEIROS, 1866, p. 68). Nesse sentido, o escravo, como propriedade, passava por sucessão ou por testamento, do mesmo modo que os outros bens (MALHEIROS, 1866, p. 72).

No inventário de Mathias Velho constam 53 escravos na descrição da Estância da Vitória, sendo 31 homens, 17 mulheres e 5 ingênuos. Tem suas origens nas divisões mulato, criolo, Moçambique,, congo e criolo.

Seus preços variam de 25:000 a 1:500\$000, sendo melhor avaliados os escravos denominados "campeiros" do que os "roceiros" e "pedreiros". As mulheres com filhos pequenos eram avaliadas com um preço mais alto, em torno de 1:000\$000 (as demais alternavam entre 300:000 e 1:000\$000), sendo seus filhos ingênuos descritos e avaliados juntamente com elas, variando entre 100:000 e 300:000.

Os dois escravos com menor preço, designados como "doente" e "cego", foram avaliados na quantia de 25:000. Como não apresentavam mais tanta capacidade de trabalho quanto escravos mais jovens e fortes, possuíam um preço menor.

No inventário aparecem os 15 escravos, os quais possivelmente se dedicavam a lides pastoris, domando gado, participando de rodeios, cujo trabalho consistia em reunir tropas para contar e marcar os animais, curar e dar sal ao gado, castrar potros e touros, tosar éguas, apartar novilhos e vacas para tropear para matadouros e charqueadas (JACQUES, 2000, p. 81). Nas estâncias de criação os trabalhadores escravos dividiam tarefas com trabalhadores semiservis (posteiros e peões). No universo rural também existiam cativos 
especializados em determinados serviços, o que se percebe pela presença de um pedreiro e de um ferreiro na unidade produtiva. Contudo, há que se considerar que provavelmente os escravos exerciam múltiplas funções no complexo da estância.

As estâncias, além de se dedicarem à produção de gado, procuravam produzir no interior de seu complexo o máximo de gêneros alimentícios possíveis. Encontram-se trabalhadores roceiros que desenvolviam a agricultura, havendo na estância também uma atafona para produzir farinha de mandioca e a casa do charque, onde se obtinha a carne seca.

Destaca-se ainda os ingênuos precedidos de suas mães, chamando a atenção dos autores que os ingênuos (crianças nascidas livres) eram arrolados juntamente com os escravos e valorados como mercadoria. Essa problemática se pretende desenvolver na seção abaixo.

\subsection{A lei de 1871 e os ingênuos de Mathias Velho}

Na segunda metade do século XIX iniciou-se no Brasil uma série de medidas políticas de abolição gradual da escravidão, sendo a Lei Eusébio de Queirós a primeira. Em 1850 o tráfico de escravos cessou e, em seu lugar, tomou vulto o tráfico interprovincial e as políticas de atração de imigrantes europeus. A partir de então, só restava no Direito Brasileiro o nascimento como fonte de escravidão (MALHEIROS, 1866, p. 41). Como já dispunha o Direito Romano, o princípio regulador era o partus sequitur, que tinha o princípio de que o filho da escrava nascia cativo, independente de o pai ser livre ou escravo (MALHEIROS, 1866, p. 41).

No ano de 1871 entrou em vigor a segunda medida, a Lei 2.040, também denominada de Lei do Ventre Livre ou Lei Rio Branco, que tinha por objetivo "estabelecer um estágio de evolução para um sistema de trabalho livre sem causar grande mudança imediata na agricultura ou nos interesses econômicos" (CONRAD, 1978, p. 113). O projeto foi apresentado na Câmara de Deputados em 12 de maio e mobilizou a elite brasileira, desencadeando um debate acalorado (PINHEIRO, 2011). Entre os oponentes do projeto de reforma estavam, principalmente, os parlamentares que representavam as províncias produtoras de café do Centro-Sul, que se apegavam ao direito de propriedade para manter seu exército de trabalhadores cativos. Nesse sentido, Barros Cobra, de Minas Gerais, defendeu que "o direito adquirido que o proprietário tinha do fruto do ventre da escrava era 
tão completo quanto o direito ao fruto da árvore ou à cria de qualquer animal de sua propridade" (CONRAD, 1978, p. 120).

A Lei 2.040, aprovada em 28 de setembro de 1871, era constituída por 10 artigos de matéria bastante complexa. A legislação estabelecia a norma, no seu Artigo $1^{\circ}$, que os filhos da mulher escrava nascidos no Império desde a aprovação da lei seriam considerados de condição livre. No entanto, a proposição liberalizante ficava obstaculizada já no seu parágrafo primeiro, o qual incumbia os senhores das mães escravas de criar e tratar os ingênuos até completarem oito anos de idade. Após este período, os senhores donos da propriedade poderiam optar entre utilizar-se dos serviços do menor até os 21 anos ou receber do Estado uma indenização pecuniária equivalente a $600 \$ 000$ (seiscentos mil reis). Este valor seria pago em títulos de renda com um juro de $6 \%$ ao ano. Conforme Conrad (1978, p. 144), “dos 400 mil ou mais ingênuos registrados até 1885, apenas 118 haviam sido confiados ao governo em troca dos ornados certificados". Com isso, os senhores quase sempre preferiram ficar com os menores, caracterizando "uma nova forma de escravidão, pois a lei não determina o número de horas de trabalho, o regime sanitário ou a alimentação a serem dados ao jovem 'escravo livre', que fica inteiramente a mercê do senhor" (MATTOSO, 1988, p. 177).

Cabia também aos senhores, conforme a Lei 2.040, criar os netos que suas escravas poderiam ter enquanto lhe prestassem serviços, sendo que essa obrigação cessaria no prazo em que os serviços de suas mães acabassem. Caso viessem a falecer, seus filhos seriam postos à disposição do governo, que poderiam entregar a associações autorizadas os ingênuos. As ditas associações teriam direito aos serviços gratuitos dos menores até seus 21 anos, podendo alugar esses serviços, embora obrigadas a criar e tratar os menores. Igualmente, deveriam constituir para cada um deles um pecúlio e procurar uma colocação apropriada quando acabado seu tempo de serviço.

Uma dessas instituições foi a Colônia Orfanológica Santa Isabel, fundada em 1874 na Zona da Mata Pernambucana. Segundo Portela (2011, p. 8), o financiamento vinha tanto dos cofres públicos quanto de doações da Santa Casa de Misericórida da Província de Pernambuco, sendo que a direção da instituição era de responsabilidade dos missionários italianos capuchinhos. Seu público-alvo eram meninos de camadas desfavorecidas: órfãos, desvalidos e ingênuos.

Instituições como essa existiram, mas acredita-se que entregar os ingênuos ao governo não foi a escolha da grande maioria dos senhores de escravos, já que aos oito anos (ou até mesmo antes) já se podia utilizar os serviços do menor. 
Nos inventários, os ingênuos não eram apenas listados, mas tinham seus serviços avaliados como os escravos adultos, mostrando a importância de sua força de trabalho. No de Mathias José Velho aparecem os ingênuos Rafael, Alfredo, Honorina, Gabriela e Alexandre - para cada um deles é atribuído um valor que varia de cem a trezentos mil réis. Pelas notas de matrícula, Gabriela havia nascido em 02 de setembro de 1875; Rafael em 07 de setembro de 1875; Honorina em 12 de outubro de 1873 e Alexandre em 03 de março de 1876. Não foi encontrada a matrícula do ingênuo Alfredo, que possivelmente devia ter idade superior à de Honorina. Os ingênuos eram valorados de acordo com a idade e a expectativa dos trabalhos futuros que poderiam vir a exercer. Nesse sentido, ao recém-nascido atribuíasse um valor inferior ao de uma criança de oito anos.

Essas crianças, sob a tutela da viúva do Major, deveriam ser criadas e cuidadas, como consta no $\S 1$ da Lei 2040. Especula-se que desde cedo foram incorporadas à rotina de trabalho de suas mães, pois, conforme Portela (2011, p. 2), as mulheres escravas tinham três dias a contar do parto para se reestabelecer e voltar ao trabalho, levando consigo seus filhos na lida doméstica. Sua infância, se é que podia ser chamada assim, não era nem de perto parecida com as das crianças brancas, sendo prematuramente inseridas no mundo adulto escravizado.

A preciosidade dessas crianças era algo latente, já que elas seriam os futuros trabalhadores nacionais (PORTELA, 2011, p. 6). A tutela nada mais seria do que uma forma de manter esses menores sob a orientação senhorial e remediar a questão da falta de mão de obra. A lei de 1871 "criou escravos disfarçados, e que acabaram libertados da mesma forma e no mesmo tempo que os outros escravos" (ZERO, 2004, p. 75). Quando da a abolição da escravidão no Brasil, em 1888, nenhum ingênuo tinha ainda completado 21 anos de idade.

Ainda que não fossem considerados propriedade, visto que eram livres, os ingênuos de Mathias José Velho foram igualmente avaliados. Um dos casos que mais chama a atenção é o do menor Alfredo. No fim da avaliação dos bens da Fazenda Nossa Senhora da Vitória, em 22 de julho de 1876, a viúva, Dona Luciana Francisca da Terra Velho, relata que após ter sido feita a descrição dos bens da Estância dos Povos, em São José do Norte, lhe fora comunicado que uma escrava de herança, de nome Mariana, havia cerca de dois meses, havia tido um filho que não se encontrava relacionado na listagem dos bens. Assim, solicitou ao procurador José Gabriel Teixeira avaliar os serviços do menor e incluí-lo no rol dos escravos da Estância Nossa Senhora da Vitória. 
ingênuo, e como seria dificil e despendiozo [...] de nova precatória somente para avaliar se tal insignificante quantia, pra que pede [...] essa dificuldade, fazendo- se avaliar neste Municipio, as futuras demissão do ingênuo filho da escrava Mariana, que deve ser baptisado com o nome de Evaristo, por tanto pois, a Supp. requer a V.S. para que a vista do [...] se sirva ordenar que os avaliadores juramentados que estão avaliando os bens existentes neste município, avaliem também por estimativa, os futuros serviços do referido ingênuo [...] (Inventário $\mathrm{N}^{\circ} 803,1876$. )

No mesmo dia é feita a avaliação do ingênuo pelos avaliadores dos bens do Major

[...] avaliadores dos bens sitos em Capivary n'esta Cidade, por eles foi dito que avaliavão os serviços do ingênuo que há de chamar-se Alfredo, filho da escrava Mariana, de que trata a petição retro na quantia de cem mil réis, e que davão o seu laudo bem fielmente na forma do juramento prestado; e assignão com o Juis [...] (Inventário $\left.\mathrm{N}^{\circ} 803,1876.\right)$

Assim, o valor atribuido aos ingênuos era diretamente proporcional a quantidade de trabalho que poderiam proporcionar ao proprietário de sua mãe até atingirem 21 anos de idade.

\section{CONSIDERAÇÕES FINAIS}

A questão que se levanta é que a lei do Ventre Livre, ao deixar os ingênuos sob o cuidado dos donos de suas mães, parece ter tido deliberadamente o intuito de reproduzir trabalhadores para os empreendimentos escravistas. Os ingênuos, conservados nas lavouras de cafezais, nas estâncias de criação de gado ou nos engenhos de açúcar, trabalhando ombro a ombro com escravos, habituariam-se àquele mundo e àquele tipo de trabalho. Por decorrência, um ingênuo não levava uma vida muito diferente daquela do escravo. Podia, inclusive, ter seu trabalho alugado e receber castigos corporais de seu amo, conforme estabelecia o Artigo 18 dos regulamentos de 13 de novembro de 1872. Os valores dos escravos ingênuos que aparecem nos inventários não representam o valor do ingênuo em si, mas dos serviços presentes e futuros que poderiam exercer.

Os descendentes de africanos nascidos sob o abrigo da Lei 2.040, embora, em tese, livres, ficaram submetidos a um estado de escravidão de fato até serem libertados juntamente aos demais escravos brasileiros em 13 de maio de 1888. Portanto, a escravatura foi suprimida antes que qualquer das crianças nascidas do Ventre Livre chegasse aos 21 anos. 


\section{REFERÊNCIAS}

BOHNS, N. M. F. Continente improvável: Artes visuais no Rio Grande do Sul do final do século XIX e meados do século XX. 383 p. Tese (Doutorado - Programa de Pós-graduação em Artes Visuais) - Universidade Federal do Rio Grande do Sul, Porto Alegre, 2005.

CARDOSO, C. F. S.; VAINFAS, R. (Org.). Domínios da história: ensaios de teoria e metodologia. 9 ed. Rio de Janeiro: Campus, 1999.

CHRISTILliNO, C. L. Os estancieiros da província de São Pedro: a pecuária em meados do século XIX no sul do império. Revista Territórios e Fronteiras, v. 3, n. 1, p. 239-259 ,2010..

CONRAD, R. Os últimos anos da escravatura no Brasil. Rio de Janeiro: Civilização Brasileira, 1978.

DAUMARD, A. História social do Brasil: Teoria e metodologia. Curitiba: Editora da Universidade Federal do Paraná, 1984.

DECRETO $\mathrm{N}^{\mathrm{o}}$ 5.135, DE 13 DE NOVEMBRO DE 1872. Disponível em: http://www2.camara.leg.br/legin/fed/decret/1824-1899/decreto-5135-13-novembro-1872551577-publicacaooriginal-68112-pe.html

Inventário de Mathias José Velho. Arquivo Público do Estado do Rio Grande do Sul (APERS), n 803, maço 35, estante 47.

LEI $\mathrm{N}^{\mathrm{o}}$ 2.040, DE 28 DE SETEMBRO DE 1871. Disponível em: http://www.planalto.gov.br/ccivil_03/Leis/LIM/LIM2040.htm

MALHEIROS, A. M. P. A escravidão no Brasil. Rio de Janeiro: Typographia Nacional, 1866.

MAGALHÃES, B. R. de. Inventários e seqüestros: fontes para a história social. Revista do Departamento de História, n. 9, p. 31-45, 1989.

MATTOSO, K. M. de Q. Ser escravo no Brasil. São Paulo: Brasiliense, 1988.

PERUSSATTO, M. K. Crias de ventre livre: Tutelas de ingênuos em um município sul-riograndense na última década do escravismo. In: Anais do X Encontro Estadual de História. Santa Maria: ANPUH, 2010.

Quando o estado intervém: Apontamentos sobre a lei do Ventre Livre de 1871. Ágora, v. 15, n. 2, p. 91-102, 2009.

PINHEIRO, A. O ventre livre em um jornal católico no século XIX. In: Revista Brasileira de História das Religiões,, v. 3, n. 9, 2011.

PORTELA, D. F. A infância brasileira em debate partir da promulgação da Lei do Ventre Livre: 1871- 1879. In: Anais do XI Congresso Luso Afro Brasileiro de Ciências Sociais. Ondina, 2011. 
SLENES, R. W. Escravos, cartórios e desburocratização: o que Rui Barbosa não queimou será destruído agora? Revista Brasileria História, v. 5, n. 10, p. 166-196,1985.

SPENNER, B. V. Arquitetura, gado e cativo: estâncias pastoris em Rio Pardo no final do século XIX. 137 p. Dissertação (Mestrado em Desenvolvimento Regional) - Universidade de Santa Cruz do Sul (UNISC), Santa Cruz do Sul, 2013.

TEIXEIRA, A. B. Inventários post mortem: possibilidades de pesquisa a partir de uma fonte plural. Mal-Estar e Sociedade, v. 5,- n. 8, p. 63-83, 2012.

ZERO, A. O preço da liberdade: caminhos da infância tutelada - Rio Claro (1871-1888). Dissertação (Mestrado em História Econômica ) - Unviersidade de Campinas (UNICAMP), Campinas, 2004.

ZETTER, R. F. V. De mútuo consentimento: os significados das relações familiares cativas para senhores e escravos na freguesia de Nossa Senhora do Rosário de Rio Pardo (1845 a 1865). 2011. 169 f. Dissertação (Mestrado em História) - Universidade Federal do Rio Grande do Sul (UFRGS), Porto Alegre, 2011. 